\title{
Using Metacognitive Awareness in Learning Vocabulary with Cloud-Based Immersive Technology
}

\author{
Soon Ming Poo and Phung Li Funn
}

\begin{abstract}
This study looks at language learning vocabulary problems in the Malaysian primary school. The problem was rooted to the teaching method of primary schools where textbook-based teaching is still practised. The objective of this study is to show the effectiveness of implementing metacognitive awareness and connectivist learning strategy in vocabulary learning by using a cloud-based immersive learning environment. Mixed methods were adopted in this study. This study involved 40 students from a Chinese primary school in Pulau Pinang, Malaysia. Data was collected from student questionnaires and interviews. The study revealed that metacognitive awareness and connectivist learning helped student in vocabulary learning. The cloud-based immersive learning enabled students to interact with learning content and engage with the vocabulary learning tasks. However, students in the primary school did not fully accept the new teaching method implemented due to the attitudes which were more concerned with exam-taking skills than with language learning.
\end{abstract}

Index Terms-Metacognition, learning vocabulary, cloud-based technology, immersive environment.

\section{INTRODUCTION}

This study investigates the effectiveness of metacognitive vocabulary learning of Malay vocabulary by Year 3 students using a cloud-based immersive platform. Vocabulary learning has been identified as an essential element to help students become more proficient in a language. It is understood that vocabulary can only be learned gradually thus, students need many encounters with unfamiliar words until they can comprehend with those words [1]. In relation with this, according to Krashen [2], vocabulary acquisition was a natural process, and it processed through comprehensible input and taught in context instead of memorization.

Several researchers [1], [3], [4] addressed that reading without explicit learning can result in incidental vocabulary development. When a student learns one thing without the intention, the incidental learning occurred [5]. According to Ahmad [3], incidental vocabulary learning requires learners' power to predict the meaning of new vocabulary from contextual hints. On other hand, intentional learning is following a carefully planned program to enhance vocabulary or grammar.

This study will look at metacognitive awareness strategies and Connectivism learning theory in vocabulary learning. There are many different theories which contribute to the vocabulary learning process [6], [7] such as constructivist

Manuscript received September 16, 2015; revised November 25, 2015.

The authors are with the Centre for Instructional Technology and Multimedia, Universiti Sains Malaysia, 11800 Gelugor, Penang, Malaysia (e-mail: soonmingpoo@yahoo.com, lifunn@usm.my). learning theory, receptive and productive vocabulary and learning theory [8], contextualized and de-contextualized learning for vocabulary acquisition theory [9] and repetition theory [10]. Metacognitive awareness is one of the vocabulary learning theories which is able to help a student when faced with unfamiliar words [11]. A student who follows the metacognitive strategy to understand what they are learning and use their own strategy tends to succeed in learning [6], [12]. Similar to the above mentioned, in Rahimi and Katal's [6] study, a metacognitive strategy assists students to learn language in a more effective and faster way compared with other learning strategies.

There were evidences showing that language learning is boring to learners [13], [14]. To overcome boredom, different platforms were created to make language learning lively and interesting such as game-based learning, e-learning, device learning and Ubiquitous learning [7], [13], [15]. Thus, virtual learning within an immersive environment is the focus of this study because an immersive world is an emerging medium in the field of education [16]. In addition, research has shown that virtual content improved engagement and learning by enabling learner interaction with learning content [17], [18]. In conjunction with virtual content, cloud-based technology comprises immersive learning that further enhances social collaboration and leads to engaging the student actively [19], [20].

\section{LITERATURE REVIEW}

\section{A. Metacognitive Awareness Learning Theory in Language}

According Ellis [21], learners have their own awareness when learning vocabulary, which includes language awareness, cognitive awareness, social awareness and culture awareness. In addition, referring to the study by Ellis [22], Hawkins [23] states that language awareness worked as a stimulus of interest on students towards the language, which will be useful in the student's life and assists the student to find the answer from questions. Besides that, strategic use of metacognitive strategy increased success in student learning [12].

According to Hawkins [23], language awareness was the means to study the language, which consisted of mother tongue languages or foreign languages. In this study, Malay Language is either the mother tongue for the Malay student or the second language of the non-Malay students. Thus, language awareness enables student in exploring and articulating vocabulary from either a mother tongue or a foreign language.

Both Ellis [21] and Dirkes [24] proposed metacognitive 
strategies of planning, monitoring, information management and evaluation. This study focuses on the three strategies that are most commonly discussed in related research, which is planning, monitoring and evaluating [24]-[26].

\section{B. Planning Strategy in Metacognitive Awareness}

The planning metacognitive strategy has a positive effect on the writing achievement by teaching the participant about the strategy of metacognitive awareness strategy before student learning [25]. Students are able to plan and apply the strategies in learning. In vocabulary learning, students should understand what they learn through an overview to the subject. In another study, although there are different in learning habit and learning pattern but setting the purpose of learning will assist students in planning their learning [27]. Each learner is unique and they have different patterns when they set up their purpose of learning by using a planning strategy. Some learners will plan well before they start the learning while some will set up the purpose after the learning or during learning. However, set up of the learning purpose early will definitely save time in learning. Besides that, planning strategy in a website is also assisted by three important elements which are the title, subtitle and menu options. These elements should be significant in order to let the student reread them time by time again during the learning process [27].

\section{Monitoring Strategy in Metacognitive Awareness}

Students should be able to monitor what they learn and what they are going to do in the learning process. In vocabulary learning, students tend to focus only on the meaning of vocabulary instead of information such as the pronunciation and usage of the vocabulary. In the vocabulary learning research by Ping and Siraj [28], respondents did not monitor their learning using different strategies such as review, record, notebook or encoding strategies. Respondents used learning strategies like a dictionary or a website to look for the meaning of the words rather than to explore the information about the vocabulary. Researchers also discussed about the lesser usage of deep processing strategies like word structure and semantic groups. During monitoring, information should be broken down into pieces so that students are able to understand, read and identify every part of the information.

\section{Evaluation Strategy in Metacognitive Awareness}

Multiple researchers showed how evaluation is implemented in instructional design. Different kinds of evaluation can be used to assess the learning outcomes of the learning. One of the evaluation methods is to give a test. The online reading materials and tasks prepared by Park and Kim [27] consisted of evaluating sessions. Participants were required to submit their answer through an online survey tool after the task is completed. On the other hand, collaborative discussion can also assess the performance of the learning. In the research of Panahandeh and Asl [25], participants were asked to get involved in some self-evaluation activities that include self-questioning, brief discussion after learning, using learning blogs to record the result of learning, have a checklist of learning and open-end questionnaires to express opinions after learning. The evaluating activities in this research consist of three stages which are self-evaluation, peer-evaluation and teacher-evaluation.

\section{E. Connectivism Learning Theory}

Virtual cloud computing enables interaction and engagement in connectivism learning theory [29]. Interaction and engagement can be promoted by using personalized learning and collaborative learning in connectivism learning theory. At the same time, immersive technology enhanced the "sense of present". Immersive environment can be presented in a realistic environment with panoramic photography [30]. However, the degree of immersion depends on how the person feels they are present in the environment but not dependent on technology.

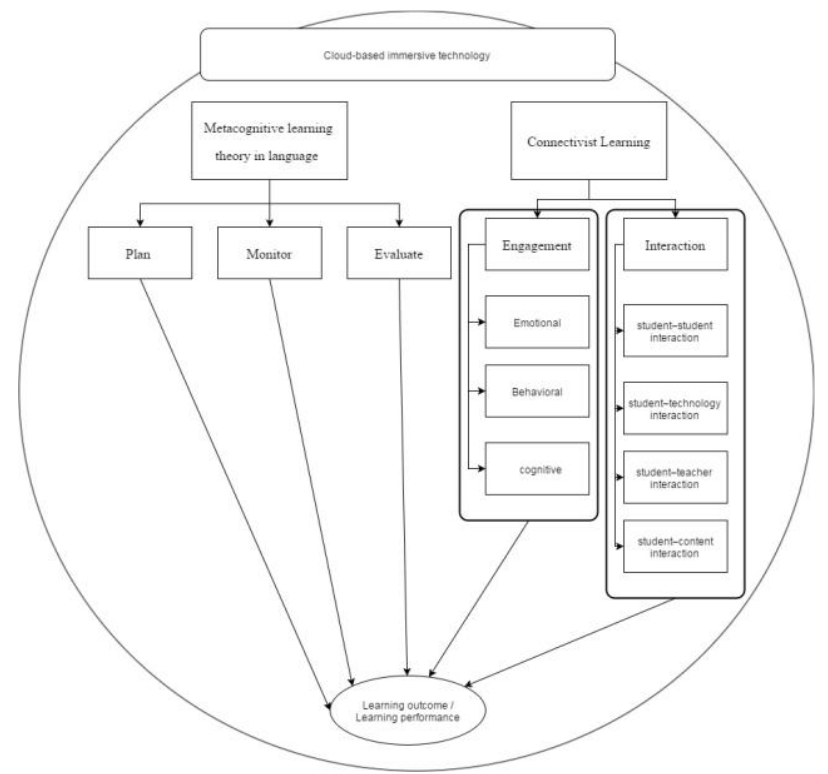

Fig. 1. Theoretical framework.

There are three types of interaction which include student-student interaction, student-technology interaction, student-teacher interaction and student-content interaction [31]-[33]. Engagement describes different behaviours, perception, thoughts and attitudes during learning [34]. Engagement is derived of three types which are emotional, behavioural and cognitive. [34], [35].

In this study, a cloud-based immersive platform is used to enable embed the connectivism learning theory in vocabulary learning. Cloud-based immersive aims to access the application in the standard network [36]. Large data will store and process on the cloud storage, which can increase the productivity of the application since the rendering process may result in application overload. Weidong, Yang [36] stated that using a graphics rendering server in cloud computing can process the workload from the application. More users or learners can reach the application through cloud applications, or cloud web.

\section{Statement OF PROBLEM}

The problem of Malay language vocabulary in primary school is that students do not adopt an effective vocabulary learning strategy. Students feel that Malay vocabulary learning is difficult and this leads to a lack of understanding of the vocabulary even though they can read by memorizing the 
words. Students also do not like or engage in the subject due to current textbook-based teaching methods. The topics covered in the Malay language are too many and vary in themes.

The theoretical framework in Fig. 1 defines the relation between theories in this study. In the cloud-based immersive environment, metacognitive awareness theory and connectivist learning theory are implemented to improve vocabulary learning performance. Metacognition is composed of planning, monitoring and evaluating while connectivist learning comprises of interaction and engagement.

\section{Methodology}

\section{A. Research Question}

The objective of this study is to create an effective learning strategy in Malay language vocabulary learning. This strategy can be acquired through the metacognitive awareness strategy and connectivist learning using a cloud-based immersive environment. The research question in this study is as follows: Is there any significant relationship between student's planning, monitoring, evaluating strategies, student's engagement and interaction to vocabulary learning performance in the cloud-based immersive learning environment?

\section{B. Participants}

Quantitative data was collected from the population of the study, which were the Year 3 students in a Primary school in Penang. The researchers obtained permissions to collect data from the institution. 40 students from Standard 3 were invited to participate in this study randomly. For triangulation purposes, qualitative data was collected through interviews with students.

\section{Design}

A mixed method triangulation design was used in this research. According to Creswell [37], researchers use the mixed method design when they want to explain in more detail where one form of data plays a supportive role to the other database. The mixed method triangulation design consists of two distinct phases: quantitative and qualitative. In this design, a researcher collects and analyzes the quantitative (numeric) data and the qualitative (text) data at the same time. Weighting for both data is usually equal and both data is merged during the interpretation or analysis. Creswell [37] stated the mixed methods researcher uses the qualitative data to provide additional sources of information not provided by the quantitative data.

\section{Instruments}

Three different instruments used in this study are a student questionnaire, student interviews and pre-test and post-test questions. The questionnaire included a set of demographics; five predictor variables (a) planning (b) monitoring (c) evaluating (d) student engagement and (e) student interaction. The instrument, which is adapted and adopted from the past study includes the questionnaire "How do You Solve Problems?" by McGee [38], "Course Engagement and Disaffection" by Chi [39], Cognitive Presence Scale for
Measuring Students' Involvement during the e-Learning Process by Kang [40] and student-instructor and student-student interaction to student learning and satisfaction by Sher [41]. The second instrument, an interview, focuses on the theme related to five independent variables of study which are planning, monitoring, evaluating, interaction and engagement. Finally, to assess the performance of participants towards the topic learned in the cloud-based immersive learning platform, 10 multiple choice questions related to the teaching content were prepared as pre-test and post-test questions.

\section{E. Materials}

This study adopted metacognitive awareness strategy and immersive technology in the Malay language learning by using a cloud-based immersive environment. Fig. 2 illustrates a few screenshots of the cloud-based immersive environment that has been developed with Haiku Learning and Pano2Vr. Fig. 2(a) is a multiple choice polling section, (b) is an immersive panorama vocabulary learning section, (c) is a goal-setting section and (d) is a discussion section.

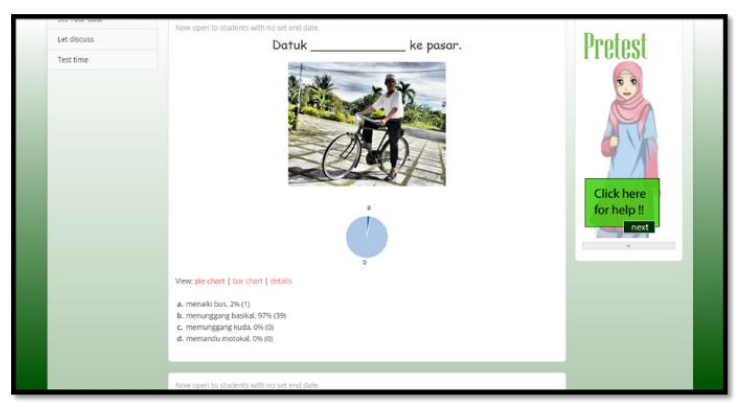

(a)

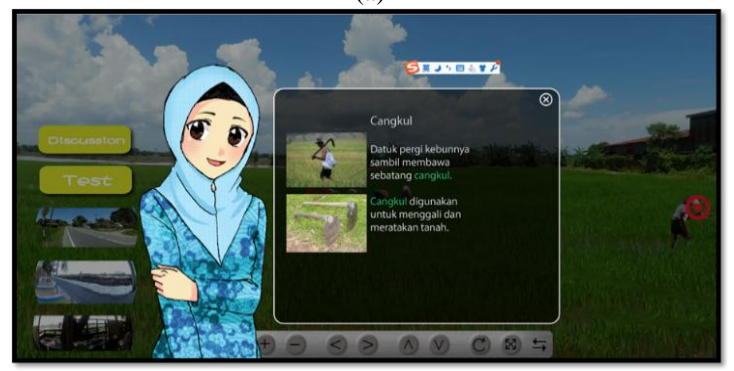

(b)

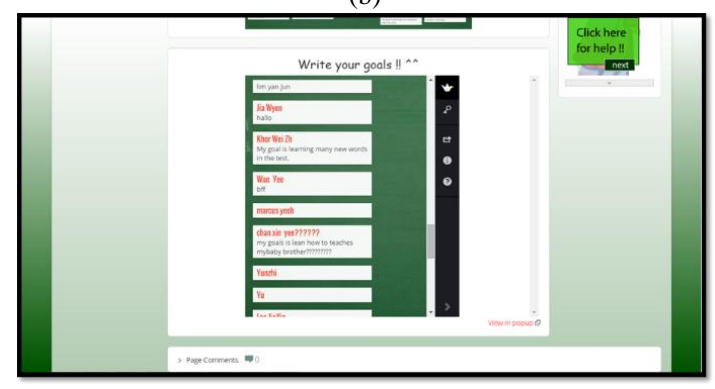

(c)

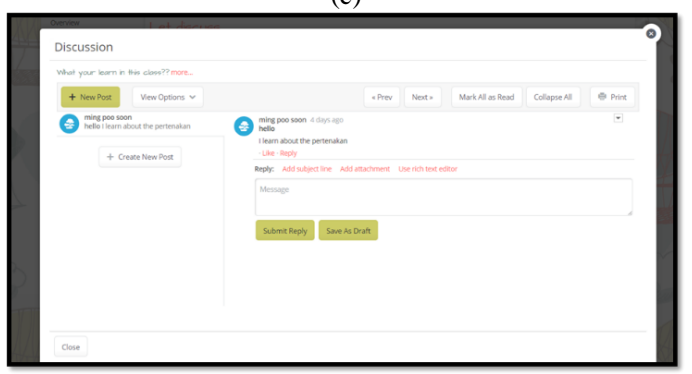

(d)

Fig. 2. Teaching materials. 
Multiple choice polling section and goal setting are approaches of planning from metacognitive awareness. By understanding the topic taught, students can have a basic understanding before the learning section.

Immersive panorama vocabulary learning section is an approach for interaction between learning material, contents and technology. This section aims to engage students in the learning task by the panorama interactive immersive environment.

The discussion section is an approach of the evaluation after the learning section. In the discussion section, students and instructor or teacher can interact with each other on the learning topic.

\section{F. Procedures}

The participants were presented to the cloud-based immersive environment. After a brief introduction to students, the researcher requested the students to do the pre-test in the cloud-based immersive vocabulary learning website. The researcher will present the content of the cloud-based immersive vocabulary learning website, which includes the activity of learning goal setting, interactive panoramic content and online discussion. The duration for the actual study was two weeks. The reason of the timeframe was to enable the participants to test the knowledge within a memory retention period. However, due to school activities and tight class schedule, the post-test was postponed by more than one month. The researcher requested the students to do the post-test in a cloud-based immersive vocabulary learning environment. Finally, participants were required to answer the questionnaire. The researcher will read and explain the questions to the students to ensure that students are able to answer the questions.

\section{G. Data Analysis}

The quantitative data was derived from the questionnaire and the pre-test and post-test questions. The qualitative data came from the student interviews. The student interviews were conducted in Mandarin and they were transcribed and translated into English. Details which not relevant to the research question were edited out during the transcription process. After transcription, the qualitative data were arranged into different themes, which followed the theoretical framework according to the research questions. This thematic analysis is widely used to analyse qualitative data. The transcript was entered into a coding sheet according to the themes from the research question. Similarities and differences between two participants can be observed in the coding sheet.

\section{RESULTS}

\section{A. Quantitative Descriptive Statistics}

The quantitative data were derived from 43 items with a scale of 1 to 5 , while missing data were defined as missing values (-9999). All the data were provided by 40 participants and the data received are processed using the computer program IBM SPSS Statistics 22 (SPSS for Windows). From these 40 participants, 35 percent of them were males and 65 percent were females.
Based on a sample of 20 Year 3 students in a pilot test, reliability for each subscale as measured by Cronbach's alpha was quite strong for planning (5 items; 0.91), evaluation (0.93), engagement (15 items; 0.96) interaction(15 items; 0.94). Only one subscale had low reliability, which is monitoring (5 items, 0.38). To increase the Cronbach alpha, an item is removed from the subscale and the Cronbach alpha is increased to become 0.88 .

In order to test the significance between the pre-test and post-test, ANOVA with Repeated Measures is used as a test method instead of an independent samples t-test because the scores are in the same group. Table I below shows the descriptive statistics for the paired pre-test and post-test. The mean of pre-test and post-test had an extremely small difference that is only 2 percent difference over 100 percent.

TABLE I: PAIRED SAMPLE STATISTICS

\begin{tabular}{llll}
\hline \hline Test & Mean & $\begin{array}{l}\text { Std. } \\
\text { Deviation }\end{array}$ & $\begin{array}{l}\text { Std. Error } \\
\text { Mean }\end{array}$ \\
\hline Pre-test & 69.23 & 18.75 & 3.68 \\
Post-test & 71.15 & 13.95 & 2.74 \\
\hline \hline
\end{tabular}

Table II shows the Tests of Within-Subject Effects. A repeated measures ANOVA with a Greenhouse-Geisser correction determined that the mean test score did not significantly differ statistically between time points ( $F$ (1.00), $25.00)=0.38, P<0.0005)$. Fig. 3 illustrates a profile plot showing the tabular results of the pre-test and post-test.

TABLE II: TESTS OF WITHIN-SUBJECT EFFECTS

\begin{tabular}{lllllll}
\hline $\begin{array}{l}\text { Time } \\
\text { Error }\end{array}$ & $\begin{array}{l}\text { Type III Sum } \\
\text { of Squares }\end{array}$ & Df & $\begin{array}{l}\text { Mean } \\
\text { Square }\end{array}$ & $F$ & Sig. & $\begin{array}{l}\text { Partial Eta } \\
\text { Squared }\end{array}$ \\
\hline 1 & 48.08 & 1.00 & 3.68 & .08 & .55 & .02 \\
2 & 3201.92 & 25.0 & 2.74 & & & \\
\hline \hline
\end{tabular}

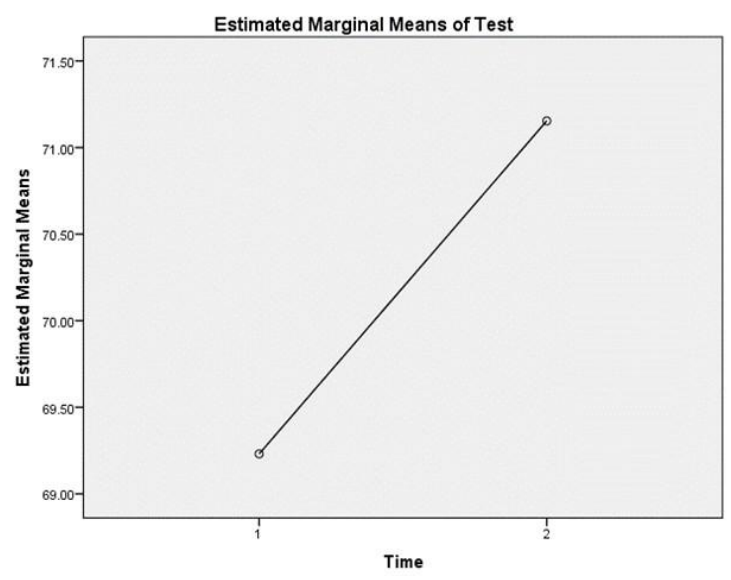

Fig. 3. Profile plot.

\section{B. Planning Strategy and Student Performance}

TABLE III: DESCRIPTIVE STATISTICS OF PLANNING STRATEGY

\begin{tabular}{lll}
\hline \hline Planning & Mean & $\begin{array}{l}\text { Std. } \\
\text { Deviation }\end{array}$ \\
\hline $\begin{array}{l}\text { I try to understand what the question is asking } \\
\text { me. }\end{array}$ & 4.09 & 1.21 \\
$\begin{array}{l}\text { I read the question more than once. } \\
\begin{array}{l}\text { I read the question over and over until I } \\
\text { understand it. }\end{array}\end{array}$ & 4.06 & 1.07 \\
$\begin{array}{l}\text { I try to understand the questions so I know what } \\
\text { to do. }\end{array}$ & 4.30 & 1.29 \\
\hline \hline
\end{tabular}


In the questionnaire, participants will be tested on their level of planning awareness by using a five point rating scale with 4 items. Table III shows the result of calculation means and standard deviation of items for planning strategy.

The results of the present study showed that there is significant positive correlation between planning strategy and post-test result. The correlation is shown in Table IV, which is $r=+.53, p<.01$.

TABLE IV: CORRELATION PLANNING AND PERFORMANCE

\begin{tabular}{lll}
\hline \hline Test & Pre-test & Post-test \\
\hline Pearson Correlation & .47 & .53 \\
Sig. (2-tailed) & .015 & .005 \\
\hline \hline
\end{tabular}

\section{Monitoring Strategy and Student Performance}

In the questionnaire, participants rate their monitoring awareness strategy in vocabulary learning from "Strongly agree" (=5) to "Strongly disagree" (=1) with 4 items. Table V shows the descriptive statistic of monitoring strategy. The mean for the items around 3-4 are represented as either "Agree" or "Not agree" to the items.

TABLE V: DESCRIPTIVE STATISTICS OF MONITORING STRATEGY

\begin{tabular}{lll}
\hline \hline Monitoring & Mean & $\begin{array}{l}\text { Std. } \\
\text { Deviation }\end{array}$ \\
\hline I find the steps I need to do this learn topic. & 3.74 & 1.35 \\
I think about all the steps as I learn topic. & 4.12 & 1.18 \\
I try to break down the topic to the necessary & 3.98 & 1.22 \\
information. & 3.95 & 1.09 \\
I identify all the important parts of the topic. & & \\
\hline \hline
\end{tabular}

From the correlation analysis of monitoring strategy and student learning performance (see Table VI), the researchers did not observe any significant correlation between them.

\begin{tabular}{lcc}
\multicolumn{3}{c}{ TABLE VI: CORRELATION MONITORING AND PERFORMANCE } \\
\hline \hline Test & Pre-test & Post-test \\
\hline Pearson Correlation & .33 & .16 \\
Sig. (2-tailed) & .12 & .46 \\
\hline \hline
\end{tabular}

\section{Evaluate strategy and student performance}

There are 5 items which assess the participant's evaluating strategy, which is shown in Table VII. The overall scale of this section is high at around 4 .

TABLE VII: DESCRIPTIVE STATISTICS OF EVALUATING STRATEGY

\begin{tabular}{lll}
\hline \hline Evaluating & Mean & $\begin{array}{l}\text { Std. } \\
\text { Deviation }\end{array}$ \\
\hline I go back and check my work. & 4.07 & 1.16 \\
I double-check to make sure I did it right. & 4.02 & 1.10 \\
I check my work all the way through the & 3.98 & 1.17 \\
problem. & 3.91 & 1.25 \\
I stop and rethink a step I have already done. & 4.16 & 1.11 \\
I make sure I complete each step. & & \\
\hline \hline
\end{tabular}

TABLE VIII: CORRELATION EVALUATING AND PERFORMANCE

\begin{tabular}{lll}
\hline \hline Test & Pre-test & Post-test \\
\hline Pearson Correlation & .28 & .37 \\
Sig. (2-tailed) & .19 & .08 \\
\hline \hline
\end{tabular}

However, the researchers cannot find any correlation between the evaluating strategy and performance by qualitative method. Table VIII shows the correlation between the evaluating strategy and performance. The researchers only can conclude that even though the evaluating process is important, this strategy alone does have any significant influence on the learning performance.

\section{E. Interaction and Student Performance}

From the descriptive statistics of subscale of interaction, the researcher found that the mean of the interaction and its sub-subscale is high, which is between 3.9 and 4. Table IX shows the mean and standard deviation of each scale.

TABLE IX: DESCRIPTIVE STATISTICS OF INTERACTION

\begin{tabular}{lll}
\hline \hline Interaction & Mean & $\begin{array}{l}\text { Std. } \\
\text { Deviation }\end{array}$ \\
\hline Student-Teacher Interaction & 3.99 & .85 \\
Student-Student Interaction & 3.87 & .96 \\
Student-Content Interaction & 4.04 & .90 \\
Student-Technology Interaction & 4.04 & 1.00 \\
Overall & 3.97 & .81 \\
\hline \hline
\end{tabular}

From Table $\mathrm{X}$, the researchers found that only student-teacher interaction has a significant correlation with student performance, which is $r=+.47, p<.01$ for the post-test. The researchers do not observe any other correlation between the other subscales.

TABLE X: CORRELATION INTERACTION AND PERFORMANCE

\begin{tabular}{llll}
\hline \hline & Test & Pre-test & Post-test \\
\hline Student-Teacher & Pearson Correlation & .456 & .470 \\
Interaction & Sig. (2-tailed) & .019 & .015 \\
Student-Student & Pearson Correlation & .241 & .369 \\
Interaction & Sig. (2-tailed) & .236 & .064 \\
Student-Content & Pearson Correlation & .138 & .131 \\
Interaction & Sig. (2-tailed) & .502 & .524 \\
Student-Technology & Pearson Correlation & .215 & .189 \\
Interaction & Sig. (2-tailed) & .302 & .365 \\
Overall & Pearson Correlation & .281 & .311 \\
& Sig. (2-tailed) & .164 & .122 \\
\hline \hline
\end{tabular}

\section{F. Engagement and student performance}

There are 3 sub-subscales under engagement, which are behavioural, emotional and cognitive. Table XI shows the descriptive statistic of engagement, which is quite high for each scale.

TABLE XI: DESCRIPTIVE STATISTICS OF ENGAGEMENT

\begin{tabular}{lll}
\hline \hline Interaction & Mean & $\begin{array}{l}\text { Std. } \\
\text { Deviation }\end{array}$ \\
\hline Behavior Engagement & 4.17 & .87 \\
Emotional Engagement & 3.97 & .89 \\
Cognitive Engagement & 3.80 & .94 \\
Overall & 3.97 & .84 \\
\hline \hline
\end{tabular}

TABLE XII: CORRELATION ENGAGEMENT AND PERFORMANCE

\begin{tabular}{llll}
\hline \hline & Test & Pre-test & Post-test \\
\hline Behavior & Pearson Correlation & .204 & .432 \\
Engagement & Sig. (2-tailed) & .318 & .027 \\
Emotional & Pearson Correlation & .416 & .509 \\
Engagement & Sig. (2-tailed) & .039 & .009 \\
Cognitive & Pearson Correlation & .328 & .329 \\
Engagement & Sig. (2-tailed) & .109 & .108 \\
Overall & Pearson Correlation & .353 & .463 \\
& Sig. (2-tailed) & .077 & .017 \\
\hline \hline
\end{tabular}

The researchers observe that behavioural engagement and 
emotional engagement have significant correlation with the student performance (see Table XII). Correlation between the behavioural engagement and student performance is $r=+.43$, $p<.05$ while the correlation between emotional engagement is $.51, p<.01$.

\section{G. Qualitative Data Analysis}

The qualitative data collected from student interviews include the main open ended questions and follow-up questions. Qualitative interviews of two participants are transcribed and entered into the coding sheet according the theme.

\section{H. Engagement Theme}

Both students show their effort and persistence in vocabulary learning tasks in the cloud-based platform. Both of them try and succeed in understanding the information which is presented in the immersive multimedia presentation. They mentioned that they can discuss and revise the lesson after this learning task. Participant A feels that the content is challenging but is willing to learn. Student A stated the following:

"It is hard, a bit hard. [...] There are some content that we never learn before".

However, participant B feels less interest and that it is troublesome to interact with the cloud-based programme. She feels it is troublesome to click and to go to another page.

\section{Interaction Theme}

In this cloud-based website, a forum was created to encourage student-teacher interaction. However, both students stated that the forum is not useful because it needs typing.

"Forum troublesome compare to write on paper.

Forum is not useful. [...] Need to type a lot".

Compared to other functions in the cloud-based website, both students found that the pre-test section was helpful in learning the vocabulary. They think that more practice helped them to learn better. Participant A mentioned that he can view anything in the panoramic interaction place. The new technology seems attractive and interesting but not all participants had same feelings toward this. Participant B claimed that she will only found this platform useful when she is not busy. She also thinks that it is annoying to turn on the computer for learning purposes.

\section{J. Metacognitive Awareness Theme}

The metacognitive awareness theme is separated into 3 sub-themes which is planning, monitoring and evaluating. In this platform, a goal setting section was provided to let the participants write down their learning goals. Both students feel that they can write down and remember what they need to do using this function. When asked about how is their planning to achieve the goal that they set, both participants have similar strategies which is read, recall and write.

"I will read first, then close the book. Then I will try to recall the words.

I will write down the words on the paper and see if I am able to spell correctly."

Both students prefer to monitor their learning by repetition. To them, repeated reading and writing can enhance the memorization and learning of the vocabulary.

"Read again and again. Then write it down and read again. Read the words before I sleep."

For awareness of evaluating the learning outcome, both participants stated that learning outcome can be evaluated by assignments and spelling tests.

\section{DISCUSSION}

The researcher observed that there were no big improvements from pre-test to post-test. This can be explained by the forgetting curve [42] which is shown in Fig. 6. Without reviewing, students can only remember $20 \%$ after one week. For this study, due to the tight schedule and school activity, the researchers could not conduct the post-test immediately after treatment. The post-test postponed for more than one month. Post-test should be done immediately, in which we assume $100 \%$ of memory retention. After one month, memory retention was only $20 \%$ and $80 \%$ of the memory was gone. Since the difference between pre-test and post-test was 2 marks, the difference of the test will be 10 marks if the memory retention is ideally $100 \%$. Assuming a new variable called New Post-test, which is created by the equation of:

\section{New Post-Test $=$ Post-Test +10 .}

To test the significance between the pre-test and a new set of post-test marks, paired sample statistics is repeated using the new data. In Table XIII, the researchers observer that repeated measures ANOVA with a Greenhouse-Geisser correction determined that the mean test score differed statistically significantly between time points $(F(1.00,25.00)$ $=14.43, P<0.001)$. If the post-test was done immediately after the treatment, a much more different result may be presented.

TABLE XIII: TESTS OF WITHIN-SUBJECT EFFECTS

\begin{tabular}{lllllll}
\hline \hline $\begin{array}{l}\text { Time } \\
\text { Error }\end{array}$ & $\begin{array}{l}\text { Type III Sum } \\
\text { of Squares }\end{array}$ & Df & $\begin{array}{l}\text { Mean } \\
\text { Square }\end{array}$ & $F$ & Sig. & $\begin{array}{l}\text { Partial } \\
\text { Eta } \\
\text { Squared }\end{array}$ \\
\hline 1 & 1848.08 & 1.00 & 1848.08 & 14.43 & .001 & .366 \\
2 & 3201.92 & 25.0 & 128.08 & & & \\
\hline \hline
\end{tabular}

It is shown that most participants can understand the topic taught and questions asked when learning the vocabulary since the mean of each item value was high, which were between 3.74 and 4.30. They were able to read and understand the topic and questions before each task of vocabulary learning. Preceding research has shown that planning strategy increases the effectiveness of learning [25]. In this study, a positive significant correlation $(r=.53, p<.01)$ between planning and post-test result prove that with planning awareness, performance of participant became better during the vocabulary learning.

In the interview, both students mentioned that the goal-setting section in the web page helped them to plan and recall what they wanted to learn. Each student had different type of plans to learn the vocabulary. Participant A mentioned that he planned to read and recall the vocabulary while participant B stated that she planned to do the revision after 
learning. Setting up purpose and planning was a starting point for successful learning and provided a focus and method for the learning [27]. The planning strategies directly influenced performance and helped students in the process of learning vocabulary. To answer the research question, there is a significant relationship between students' planning strategies to vocabulary learning performance in the cloud-based immersive learning environment.

From descriptive statistics, the researchers found that the student actually has the monitoring awareness during vocabulary learning since the mean of the every item was considered high (3.74 4.12). However, there is no significant correlation between monitoring strategy and student performance $(r=.15)$. This may due to the fact that not all students use the strategies effectively in their vocabulary learning. Every student has his or her own way to learn the vocabulary that can be justified from the feedback in the interview, which will be discussed in the following section.

In the interview section, both students stated that their learning strategies were repeated reading until they remember. This kind of learning strategy was to improve memorization by repetition. It was not effective compared to other strategies such as making a connection with the graphic and the use of context clues. Even though graphics and interaction were provided in the website, the participants preferred to use their own method to learn the vocabulary, which was memorization. This kind of surface approach that was to memorize key terms in order to answer questions was adopted by students instead of a deeper approach that was to understand the message in that passage could be seen in the work of Lim [43]. This shows that the current teaching method in the Malay language class leaned towards the memorizing method. From the findings, the researchers found that the monitoring strategy was not related to vocabulary learning. However, further study should focus on teaching students the more effective learning strategy to monitor their learning.

Participants had a high evaluating awareness during vocabulary learning where the researchers found that the mean of each item of the evaluating awareness strategies was high (3.98 4.16).

When participants were asked about the strategy they used to determine whether their learning plan worked, they reflected that they would determine it by the assignment, spelling and test. This shows that students had the awareness of the evaluating strategy and knew what was the evaluating method. The overall scale of evaluating strategy proves that students had the awareness to evaluate their learning outcome.

However, the correlation between evaluating strategies and vocabulary learning performance is low $(r=.37)$. According to Lim [43], Malaysian primary schools adopted the learning style in which the exam result was everything which the researcher can prove from the interview in this research. In addition, one of the participants said that, "if you can score full marks in examination mean you have learned something". Although it is good to score high in the examination, however, too much concern on the result leads to the development of exam-taking skill only rather than the comprehension, reading and writing skill.

The participants had the awareness of evaluating their learning. However, evaluation should cover the four different perspectives that include spelling, reading, comprehension and writing.

The findings from the descriptive statistics showed that the interaction between the scale and its sub-scale was high (3.9 4). Participants were satisfied with the interaction in the cloud-based immersive learning, which included the practice, goal setting section, panoramic interaction section, discussion and the post-test.

However, the researchers found only the student-teacher interaction significantly correlated with the student performance in vocabulary learning that helped students to give feedback to the teacher. However, there was no correlation with the other student interaction, which included the student-content, student-student and student-technology interactions.

From the interview section, the researchers found that participants who had the least interest towards the cloud-based immersive learning platform was due to it being "troublesome" and that it was a waste of time. This again was because students in Malaysia put in too much effort in their achievement in examination only than to truly understand the meaning of vocabulary or a message. According to Lim [43], students were less talkative, book smart and exam-ready in the Chinese classroom learning culture in Malaysia was. Similar with Hong Kong, some Chinese schools in Malaysia adopted the strategy of rote memorization and careful exam-taking skills [43]. Due to the reasons mentioned above, learning with the cloud-based immersive platform was less effective compared to the simple vocabulary list or textbook-based method in Malaysia.

From both the quantitative and qualitative findings, the participants engaged in three perspectives which included behaviour, emotional and cognitive engagement. In the descriptive statistics, there are high means of each sub-scale of the engagement that is around 3.97 to 4.1. The researchers designed and developed the class to support students' engagement such as structure or the course. Technology engaged participants to be more interested in the vocabulary learning but not every participant accepted it. For some students, interaction with the computers was harder compared to textbook-based learning. The usage of keyboard and mouse to interact with content consumed more time. Besides that, not everyone had a computer device at home.

From the correlation analysis, both behavioural engagement $(r=.43, p<0.05)$ and the emotional engagement $(r=.51, p<0.01)$ had significant correlation to the student's vocabulary learning performance. This meant that students could really focus and put their effort into learning during the learning task. They were behaviouraly engaged to the virtual learning platform that had a different type of content and learning task. Besides that, students showed greater interest and emotional engagement when using a cloud-based immersive platform.

However, cognitive engagement had no significant correlation with the student performance. This may be due to the limited practice, quiz and test provided which we can justify from the student's feedback in the interview. They felt that the questions were enough and more questions should be provided. 


\section{CONCLUSION}

Results of the study showed that planning awareness strategy, interaction and engagement had correlation with vocabulary learning. From the findings and analysis, the cloud-based immersive learning helped students to interact with learning content and engage with the vocabulary learning activities. Although the researchers tried to implement the learning method from another country, Malaysian students might have a different feeling and acceptance to the learning method. Due to the culture that focused on the student's examination achievement, students preferred to learn about exam-taking skills than the meaning behind the knowledge. Therefore, there is a need to transform traditional practice of learning activities and mindset for a better learning environment that are not solely results-oriented. On the whole, this study gave the researchers and the instructional designers an insight to the learning approach using cloud and immersive technology.

\section{ACKNOWLEDGMENT}

The authors would like to thank everyone who assisted in the research.

\section{REFERENCES}

[1] R. Brown, R. Waring, and S. Donkaewbua, "Incidental vocabulary acquisition from reading, reading-while-listening, and listening to stories," Reading in a Foreign Langauge, vol. 20, no. 2, 2008.

[2] S. D. Krashen, "Principles and practice in second language acquisition," Pergamon, 1982.

[3] J. Ahmad, "Intentional vs. incidental vocabulary learning," International Association of Research in Foreign Language Education and Applied Linguistics ELT Research Journal, vol. 1, no. $1,2012$.

[4] R. J. Ponniah, "Incidental acquisition of vocabulary by reading," The Reading Matrix, vol. 11, no. 2, 2011.

[5] J. C. Richards and R. Schmidt, "Longman dictionary of language teaching and applied linguistics, in Longman dictionary of language teaching and applied linguistics," Pearson Education Limited Great Britain, 2010,

[6] M. Rahimi and M. Katal, "Metacognitive strategies awareness and success in learning English as a foreign language: An overview," Procedia - Social and Behavioral Sciences, vol. 31, pp. 73-81, 2012.

[7] D. A. Wierson, "Effects of an iPad application on vocabulary and comprehension in a sixth-grade classroom," Southwest Minnesota State University: Ann Arbor, 2013, p. 70.

[8] K.-H. Hung, "The design and development of an education-designed massively multiplayer online role-playing game (EDD MMORPG) for young Taiwanese Mandarin-speaking learners learning English vocabulary words," 2011, Teachers College, Columbia University: Ann Arbor, p. 291.

[9] I. S. P. Nation, Learning Vocabulary in Another Language, Cambridge University Press, 2001.

[10] Q. Wu, "Designing a smartphone app to teach English (L2) vocabulary," Computers \& Education, vol. 85, pp. 170-179, 2015.

[11] J. M. Harmon, E. Buckelew-Martin, and K. D. Wood, "The cognitive vocabulary approach to word learning," English Journal, vol. 100, no. 1, pp. 100-107, 2010.

[12] P. L. Funn, "Self-regulated learning in an e-learning environment in a Malaysian University, in Curtin University, School of Education," 2011, p. 249.

[13] A. N. Alshammari, "A quantitative study of the impact of immersive game-based learning on enhancing vocabulary instruction and acquisition for English language learners," Western Illinois University: Ann Arbor, 2013, p. 95.

[14] A. Ruphina, J. W. Ting, and Y. Li, "Serious game motivation in an EFL classroom in Chinese primary school," TOJET: The Turkish Online Journal of Educational Technology, vol. 11, no. 1, 2012.

[15] C. C. Lin and Y. C. Yu, "L learners' cognitive load of learning vocabulary on mobile phones," presented at the 20th International Conference on Computers in Education, 2012.
[16] K. F. Hew and W. S. Cheung, "Use of three-dimensional (3-D) immersive virtual worlds in K-12 and higher education settings: A review of the research," British Journal of Educational Technology, vol. 41, no. 1, pp. 33-55, 2010.

[17] A.-L. Lee, K. W. Wong, and C. C. Fung, "How does desktop virtual reality enhance learning outcomes? A structural equation modeling approach," Computers \& Education, vol. 55, no. 4, pp. 1424-1442, 2010.

[18] J. Grieu et al., "GE3D: A virtual campus for technology-enhanced learning in Education Engineering (EDUCON)," 2010 IEEE, 2010.

[19] L. Huang, F. Liu, and C. Liu, "Design and research on collaborative learning program based on cloud-services," presented at the 2012 2nd International Conference on Computer and Information Application (ICCIA 2012), 2012.

[20] C. E. Pereira, S. Paladini, and F. M. Schaf, "Control and automation engineering education: Combining physical, remote and virtual labs," presented at 2012 9th International Multi-Conference on Systems, Signals and Devices (SSD), 2012.

[21] G. Ellis, "Developing metacognitive awareness: The missing dimension," School of Education, University of Nottingham, 1999.

[22] E. M. Ellis, "Language awareness and its relevance to TESOL," University of Sydney Papers in TESOL, vol. 7, pp. 1-23, 2012.

[23] E. Hawkins, Awareness of Language: An Introduction, Cambridge University Press, 1987

[24] M. A. Dirkes, "Metacognition: Students in charge of their thinking," Roeper Review, vol. 8, no. 2, pp. 96-100, 1985.

[25] E. Panahandeh and S. E. Asl, "The effect of planning and monitoring as metacognitive strategies on Iranian EFL learners' argumentative writing accuracy," Procedia - Social and Behavioral Sciences, vol. 98, pp. 1409-1416, 2014.

[26] M. T. Yeganeh, "Metacognitive listening strategies awareness in monolingual versus bilingual EFL learners," Procedia - Social and Behavioral Sciences, vol. 70, pp. 1787-1793, 2013.

[27] H.-R. Park and D. Kim, "Reading-strategy use by English as a second language learners in online reading tasks," Computers \& Education, vol. 57, no. 3, pp. 2156-2166, 2011.

[28] A. M. Ping, and S. Siraj, "Exploring self-regulatory strategies for vocabulary learning among Chinese EFL learners," Procedia - Social and Behavioral Sciences, vol. 47, pp. 1211-1215, 2012.

[29] L. Sun, T. Fukuda, and B. Resch, "A synchronous distributed cloud-based virtual reality meeting system for architectural and urban design," Frontiers of Architectural Research, vol. 3, no. 4, pp. 348-357, 2014.

[30] C. Weissig et al., The Ultimate Immersive Experience: Panoramic 3D Video Acquisition, in Advances in Multimedia Modeling, Springer Berlin Heidelberg, pp. 671-681, 2012.

[31] Á. F. Agudo-Peregrina et al., "Can we predict success from log data in VLEs? Classification of interactions for learning analytics and their relation with performance in VLE-supported F2F and online learning," Computers in Human Behavior, vol. 31, pp. 542-550, 2014.

[32] T. Anderson et al., Protective Wrapper Development: A Case Study, in COTS-Based Software Systems, Heidelberg, Berlin: Springer, pp. 1-14, 2003.

[33] K. C. V. Ekwunife-Orakwue and T.-L. Teng, "The impact of transactional distance dialogic interactions on student learning outcomes in online and blended environments," Computers \& Education, vol. 78, pp. 414-427, 2014.

[34] S. M. Fulmer et al., "Interest-based text preference moderates the effect of text difficulty on engagement and learning," Contemporary Educational Psychology, vol. 41, pp. 98-110, 2015.

[35] A. J. Fredicks and A. H. Paris, "School engagement: Potential of concept, state of the evidence," Review of Educational Research, vol. 74 , no. $1,2004$.

[36] S. Weidong et al., "Scalable support for 3D graphics applications in cloud," presented at 2010 IEEE 3rd International Conference on Cloud Computing (CLOUD), 2010.

[37] J.W. Creswell, Educational Research: Planning, Conducting, and Evaluating Quantitative and Qualitative Research, Addison Wesley, 2012.

[38] B. C. Howard et al., "Metacognitive self-regulation and problem-solving: Expanding the theory base through factor analysis," presented at the Annual Meeting of the American Educational Research Association, New Orleans, LA, 2000.

[39] U. Chi, E. A. Skinner, and T. A. Kindermann, "Engagement and disaffection in the college classroom: Construction and validation of a measurement tool to assess students' motivation to learn," 2010.

[40] M. H. Kang, J. U. Park, and S. Y. Shin, "Developing a cognitive presence scale for measuring students' involvement during e-learning 
process," presented at AECT International Convention, Ahaheim, California, 2007

[41] A.Sher, "Assessing the relationship of student-instructor and student-student interaction to student learning and satisfaction in web-based online learning environment," Journal of Interactive Online Learnin, vol. 8, no. 2, 2009.

[42] S. M. Stahl, "Play it again: The master psychopharmacology program as an example of interval learning in bite-sized portions," CNS Spectrums, vol. 15, no. 8, pp. 491-504, 2010.

[43] T. D. Lim, "Analyzing Malaysian English classrooms: Reading, writing, speaking and listening teaching strategies," College of Education University of Washington, 2013, p. 58.

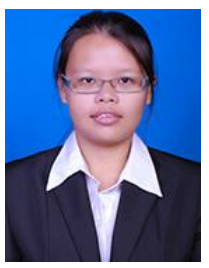

Soon Ming Poo was born in 1991. Her got her master's degree in instructional multimedia from Universiti Sains Malaysia. Her current research area is immerging technology in education technology.

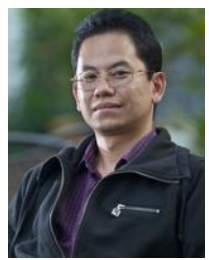

Phung Li Funn is senior lecturer at Centre for Instructional Technology and Multimedia, Universiti Sains Malaysia. He obtained his doctor of philosophy (education) in School of Education, Curtin University, Australia 2011. His current research area included self-regulated learning, e-learning, instructional, educational technology. 